UAD Jurnal Genre

Universitas

Vol. 3, No. 1, February 2021, 24-31

$10.26555 /$ jg.v\%vi\%i.2180

Ahmad Dahlan

http://journal2.uad.ac.id/index.php/genre/index

\title{
Analisis kesalahan berbahasa tataran sintaksis pada pidato Presiden Jokowi dalam Sidang Umum PBB
}

\author{
Fanesia Debi a,1, ${ }^{*}$, Latifah Riyaningrum b,2, Luthfiana Yunita Dewi c,3, Chafit Ulyac, 4 \\ a Pendidikan Bahasan dan Sastra Indonesia, Fakultas Keguruan dan Ilmu Pendidikan, Universitas Sebelas Maret; \\ b Pendidikan Bahasan dan Sastra Indonesia, Fakultas Keguruan dan Ilmu Pendidikan, Universitas Sebelas Maret; \\ c Pendidikan Bahasan dan Sastra Indonesia, Fakultas Keguruan dan Ilmu Pendidikan, Universitas Sebelas Maret; \\ ${ }^{4}$ Pendidikan Bahasan dan Sastra Indonesia, Fakultas Keguruan dan Ilmu Pendidikan, Universitas Sebelas Maret. \\ 1fanesiadebi1102@student.uns.ac.id*; ${ }^{2}$ latifahriyani28@student.uns.ac.id; ${ }^{3}$ lutfhianayd@student.uns.ac.id; \\ chafit@staff.uns.ac.id \\ *Correspondent Author
}

\section{ARTICLE INFO}

Article history

Received : Desember 2020

Revised : Januari 2021

Accepted : Februari 2021

Keywords

Speech_1

Errors of language_2

Syntax_3

sentences_4
ABSTRACT

The purpose of this research is (1) to describe the speaking errors in terms in the syntax on a speech the President Jokowi of the UN general assembly contained in the portal news Kompas.com Edition 23 September 2020 (2) to provide improvements in the syntax to the speech of the President Jokowi of the UN general assembly contained in the portal news Kompas.com Edition of 23 December 2020. This research is descriptive qualitative research. The data techniques used is the technique of intensive reading and technique of note. The results of the error in terms in the syntax show that the error in terms most found on the type of error the use of excessive or redundant. In addition, there is also a type of error in another language i.e. the use of prepositions that is not appropriate, a double, the omission of conjunctions, the use of conjunctions excessive, and the use of foreign terms

\section{Pendahuluan}

Kesalahan berbahasa merupakan penggunaan bahasa yang menyimpang dari kaidah bahasa yang digunakan. Menurut Mubarokah dan Rosita (2019), bahasa merupakan faktor penjamin keberlangsungan komunikasi sosial baik itu tulis maupun lisan. Penggunaan bahasa yang baik dan benar dalam komunikasi memiliki tujuan agar suatu informasi dapat tersampaikan dengan baik. Bahasa sebagai alat komunikasi dapat berupa bahasa lisan dan bahasa tulis. Untuk dapat berbahasa dengan baik maka masyarakat diharuskan menguasai keterampilan berbahasa.

Terdapat empat keterampilan berbahasa, yaitu keterampilan membaca, keterampilan berbicara, keterampilan menyimak, dan keterampilan menulis. Salah satu keterampilan berbahasa yang cukup kompleks adalah keterampilan menulis. Dalam keterampilan menulis dibutuhkan ketelitian dan pengetahuan yang luas agar dapat menuangkan ide ke dalam bahasa tulis secara kohesi, koheren, serta sesuai kaidah kebahasaan.

Salah satu contoh keterampilan menulis yaitu menulis teks pidato. Menurut Somad dan Indriani (2010: 4), pidato adalah kegiatan berbicara dihadapan banyak orang untuk menyampaikan suatu masalah agar dapat mencapai tujuan tertentu. Suatu pidato dapat tersampaikan dengan baik apabila teks pidato ditulis dengan menggunakan kalimat yang terstruktur sesuai kaidah kebahasaan, sehingga pesan yang hendak disampaikan dalam pidato tersebut dapat diterima masyarakat dengan baik. 
Pidato menjadi salah satu hal yang wajib ketika terdapat sebuah acara, baik untuk menyatakan selamat, menyambut tamu, memperingati hari tertentu, atau yang lainnya. Menurut Tarigan (2008:16) tujuan dari pidato adalah 1) menyampaikan informasi (informatif), 2) meyakinkan dan memengaruhi sikap pendengar (persuasif), 3) menghibur pendengar (rekreatif), dan 4) menekankan aspek-aspek pendidikan (edukatif).

Namun, pada kenyataannya di lingkungan masyarakat masih terdapat beberapa kesalahan dalam penulisan teks pidato. Hal ini sesuai dengan penelitian yang dilakukan oleh Lubis (2018) yang menyatakan bahwa terdapat kesalahan penulisan teks pidato pada bagian pembuka, isi, dan penutup. Kesalahan ini terjadi karena kurangnya pemahaman penulis mengenai cara membuat teks pidato yang baik dengan menggunakan kalimat yang strukturnya lengkap. Kajian mengenai penulisan kalimat yang efektif dan sistem dipelajari dalam aspek sintaksis.

Dari hasil penelitian yang sebelumnya maka pada penelitian ini peneliti akan melakukan analisis kesalahan berbahasa aspek sintaksis pada teks pidato Presiden Joko Widodo dalam Sidang Umum PBB ke-75 pada tahun 2020. Tujuan dilakukannya analisis ini adalah agar dapat mengidentifikasi kesalahan berbahasa pada aspek sintaksis dan dapat melakukan perbaikan atas kesalahan tersebut. Sehingga dapat menghasilkan teks pidato yang sistematis dengan susunan kalimat yang efektif.

\section{Kesalahan Berbahasa}

Kesalahan berbahasa dapat terjadi akibat pemakai bahasa yang tidak memperhatikan kaidah berbahasa sebagai hasil akhir dari kegiatan komunikasi (Johan, 2017:241). Kesalahan berbahasa seringkali tidak dapat dihindari. Maka dari itu, sebagai pemakai bahasa hendaknya menanggapi dengan bijak dengan cara menjadikan kesalahan tersebut menjadi sebuah proses untuk lebih giat belajar berbahasa. Corder (dalam Johan, 2017:242) berpendapat bahwa kesalahan pasti pernah dilakukan seseorang yang sedang belajar berbahasa.

Parera (dalam Johan, 2017:241) mengemukakan bahwa terdapat dua perbedaan kesalahan berbahasa yaitu error dan mistake. Error dapat terjadi akibat kurangnya penguasaan kaidah kebahasaan yang benar. Mistake terjadi akibat ketidakmampuan merealisasikan kaidah berbahasa yang sebelumnya telah dikuasai.

\section{Analisis Kesalahan Berbahasa}

Analisis kesalahan berbahasa merupakan kegiatan mengumpulkan, mengklasifikasi, dan mengevaluasi kesalahan berbahasa. Tarigan dan Sulistiyaningsih (dalam Johan, 2017:243) berpendapat bahwa analisis kesalahan berbahasa adalah prosedur kerja peneliti yang meliputi kegiatan pengumpulan sampel kesalahan berbahasa, mengidentifikasi kesalahan, menjelaskan bagaimana bisa terjadi kesalahan pada sampel, mengklasifikasi berdasarkan kategori kesalahan, serta yang terakhir mengevaluasi tingkat keseriusan kesalahan berbahasa yang didapat pada sampel tersebut.

\section{Kesalahan Berbahasa Tataran Sintaksis}

Sintaksis merupakan cabang ilmu linguistik yang fokus kajiannya berupa kata dan hubungannya dengan kata atau unsur lain sebagai satuan kalimat atau ujaran yang lengkap (Chaer, 2012: 206). Menurut Sawalmeh (2013), Word order in the syntactic arrangement are words in phrases, clauses, and sentences. Kajian sintaksis memperhatikan susunan kata dalam dalam frasa, klausa, dan kalimat. Maka dari itu, dalam penulisan sebuah kalimat hendaknya 
memperhatikan struktur kalimat yang lengkap sesuai kaidah kebahasaan.

Menurut Setyawati (2013: 15), kesalahan berbahasa tataran sintaksis terjadi karena adanya penggunaan preposisi yang tidak tepat, penggunaan unsur yang berlebihan, penggunaan superlatif yang berlebihan, susunan kata yang tidak tepat, penggunaan resiprokal yang tidak tepat, dan penjamakan yang ganda. Sementara itu, kesalahan pada bidang kalimat meliputi: kalimat tidak bersubjek, kalimat tidak berpredikat, antara predikat dan objek tersisipi, penggandaan subjek, urutan yang tidak paralel, kalimat yang bersifat analisis kesalahan berbahasa tataran sintaksis dapat dibandingkan dengan artikel penelitian ambigu, kalimat yang tidak logis, penggunaan konjungsi yang berlebihan, penghilangan konjungsi, penggunaan kata tanya yang tidak perlu, dan penggunaan istilah asing.

Artikel tentang terdahulu yang berjudul Analisis Kesalahan Berbahasa Indonesia Secara Sintaksis dalam Proses Diskusi Siswa Kelas IV SDN Miri. Pada penelitian tersebut ditemukan beberapa kesalahan berbahasa, seperti terdapat kesalahan pada frasa dan kalimat. Kesalahan pada frasa meliputi kesalahan penghilangan preposisi serta penggunaan bentuk superlatif yang berlebihan. Terdapat pula kesalahan dalam kalimat, seperti penggunaan istilah asing, penghilangan konjungsi, penggunaan kata hubung yang tidak tepat, serta adanya pengaruh bahasa daerah.

\section{Metode}

Metode yang digunakan dalam penelitian ini adalah kualitatif dengan pendekatan deskriptif. Teknik pengumpulan data yang digunakan adalah teknik simak dan catat. Teknik membaca intensif untuk memperoleh data dengan membaca secara intensif penggunaan bahasa, sedangkan teknik catat untuk mencatat kata atau kalimat untuk dianalisis. Data dalam penelitian ini berupa pidato presiden Jokowi dalam sidang PBB yang termuat di portal berita Kompas.com edisi 23 September 2020.

\section{Hasil dan Pembahasan}

Sintaksis merupakan salah satu cabang bahasa yang mempelajari tentang frasa, klausa, dan kalimat. Menurut Ramlan dalam Hasanudin (2018:20) sintaksis merupakan cabang ilmu bahasa yang membahas wacana, kalimat, klausa, dan frasa. Sementara itu, menurut Kridalaksana dalam Hasanudin (2018:21) sintaksis ialah cabang linguistik yang mempelajari pengaturan dan hubungan antara kata dan kata,atau antara kata dan satuan-satuan yang lebih besar, atau antar satuan yang lebih besar itu di dalam bahasa. Artinya sintaksis itu ialah cabang ilmu bahasa yang mempelajari bagaimana pengaturan dan hubungan kata-kata dalam membentuk frasa, klausa, dan kalimat.

Berdasarkan pendapat Setyawati (2013: 15) Analisis kesalahan berbahasa adalah prosedur kerja yang biasa digunakan oleh peneliti atau guru bahasa yang meliputi: kegiatan mengumpulkan sampel kesalahan, mengidentifikasi kesalahan yang terdapat dalam sampel, menjelaskan kesalahan tersebut, mengklasifikasi kesalahan tersebut, dan mengevaluasi taraf keseriusan kesalahan itu. Kesalahan berbahasa dalam bidang frasa dapat disebabkan oleh berbagai hal, diantaranya: (a) adanya pengaruh bahasa daerah, (b) penggunaan preposisi yang tidak tepat, (c) kesalahan susunan kata, (d) penggunaan unsur yang berlebihan atau mubazir, (e) penggunaan superlatif yang berlebihan, (f) penjamakan ganda, dan (g) penggunaan bentuk resiprokal yang tidak tepat (Setyawati, 2013:68). Kriteria kesalahan penggunaan kalimat diklasifikasikan berdasarkan faktor penyebabnya yaitu: (a) kalimat yang tidak bersubjek, (b) kalimat yang tidak berpredikat, (c) kalimat yang buntung (tidak bersubjek dan tidak berpredikat), (d) antara predikat dan objek yang tersisipi, (e) kalimat yang tidak logis, (f) kalimat yang ambiguitas, (g) penghilangan konjungsi, (h) penggunaan konjungsi yang berlebihan, (i) urutan kalimat yang tidak 
paralel, (j) penggunaan istilah asing, dan (k) penggunaan kata tanya yang tidak perlu (Setyawati, 2013: 76).

Analisis kesalahan berbahasa tataran sintaksis pada pidato Presiden Joko Widodo dalam Sidang Umum PBB diklasifikasikan, dianalisis serta diuraikan sebagai berikut.

a. Kesalahan Penggunaan Struktur Frasa

1) Penggunaan Preposisi yang Tidak Tepat

Dalam sintaksis, preposisi terdapat di depan nomina, adjektiva, atau adverbia yang secara sistematis menandai hubungan makna antara konstituen di depan dan di belakang preposisi tersebut.

"Diusia PBB yang ke-75 ini, kita patut bertanya, apakah dunia yang kita impikan tersebut sudah tercapai?"

Penggunaan preposisi yang bercetak miring pada kalimat di atas tidak tepat. Preposisi dimenyatakan penanda hubungan tempat. Preposisi yang tepat yaitu menggunakan padakarena menyatakan hubungan waktu.

Perbaikan kalimat di atas sebagai berikut:

"Pada usia PBB yang ke-75 ini, kita patut bertanya apakah dunia yang kita impikan sudah tercapai?"

2) Penggunaan Unsur yang Berlebihan atau Mubazir

Pada pidato Presiden Joko Widodo dalam sidang PBB terdapat penggunaan kata yang memiliki makna yang sama atau bersinonim dalam sebuah kalimat. Sehingga hal tersebut menjadikan kalimat bersifat mubazir atau tidak hemat. Berikut ini merupakan beberapa kesalahan penggunaan unsur kalimat yang mubazir atau berlebihan.

a) "75tahun yang lalu PBB dibentuk agar perang besar, perang dunia II tidak terulang kembali".

Penggunaan kata yang bercetak miring di atas dianggap mubazir karena tidak hemat.

Perbaikan kalimat tersebut adalah sebagai berikut;

"75 tahun yang lalu PBB dibentuk agar perang dunia II tidak terulang kembali".

b) "Persamaan derajat inilah yang ditekankan oleh Bapak bangsa Indonesia Soekarno, Bung Karnosaat Konferensi Asia Afrika di Bandung tahun 1955 yang menghasilkan Dasasila Bandung."

Pada kasus di atas terdapat pengulangan nama Soekarno dalam satu kalimat. Sehingga bersifat mubazir atau tidak hemat.

Perbaikan atas kalimat tersebut adalah sebagai berikut.

"Persamaan derajat inilah yang ditekankan oleh Bapak bangsa Indonesia yaitu Ir. Soekarno saat Konferensi Asia Afrika di Bandung tahun 1955 yang menghasilkan Dasasila Bandung".

c) Penjamakan yang Ganda

Dalam sebuah kalimat hendaknya menggunakan satu penanda jamak. Apabila dalam sebuah kalimat sudah terdapat penanda jamak, maka tidak perlu diberi 
kata ulang, begitu pula sebaliknya. Contoh penjamakan ganda terdapat pada kalimat berikut.

Yang mulia para pemimpinnegara-negaraanggota PBB".

Pada kalimat tersebut terdapat penanda jamak yaitu paradan kata ulang yaitu negara-negara.Sehingga kalimat menjadi tidak efektif. Penulisan kalimat yang benar adalah dengan menggunakan penanda jamak saja, tidak perlu ditambahkan kata ulang.

Perbaikan atas kalimat tersebut adalah sebagai berikut.

"Yang mulia para pemimpin negara anggota PBB".

b. Kesalahan Penggunaan Struktur Kalimat

1) Penghilangan Konjungsi

"Yang mulia tahun ini Indonesia juga merayakan kemerdekaan yang ke-75 tahun dan sudah menjadi tekad kami Indonesiauntuk terusberkontribusi bagiperdamaian dunia sesuai amanah konstitusi".

Kalimat di atas terdapat penghilang konjungsi sebagai. Selain itu, terdapat penghilangan beberapa kata yang semestinya dapat melengkapi kalimat tersebut. Penulisan kata yang dicetak miring kurang lengkap susunannya, sehingga artinya tidak berterima. Seharusnya disisipi konjungsi sebagaidan diikuti kata bangsa.

Perbaikan kalimat tersebut adalah sebagai berikut.

"Yang mulia, tahun ini bangsa Indonesia juga merayakan kemerdekaan yang ke-75 tahun, dan sudah menjadi tekad kami sebagai bangsa Indonesia untuk selalu berkontribusi dalam perdamaian dunia sesuai amanah konstitusi".

2) Penggunaan Konjungsi yang Berlebihan

Dalam sintaksis, konjungsi digunakan untuk menganalisis berdasarkan unsur yang digabungkan. Apakah konjungsi tersebut menghubungkan klausa dengan klausa, 
maupun kalimat dengan kalimat dalam tataran kalimat majemuk setara. Contoh penggunaan konjungsi yang berlebihan adalah sebagai berikut.

a) "Konflik masih terjadi di berbagai belahan dunia, kemiskinan danbahkankelaparan masih terus dirasakan".

Pada kalimat di atas terdapat penggunaan konjungsi yang berlebihan yaitu konjungsi danyang kemudian diikuti kata penghubung bahkan. Sebaiknya penulisan sebuah kalimat hanya menggunakan satu kata penghubung saja, agar kalimat menjadi efektif.

Perbaikan kalimat tersebut adalah sebagai berikut.

"Konflik masih terjadi di berbagai belahan dunia, kemiskinan bahkan kelaparan masih terus dirasakan".

b) "Jika perpecahan dan rivalitas terus terjadi, maka saya khawatir, pijakan bagi stabilitas dan perdamaian yang lestari akan goyah, atau bahkanakan sirna".

Pada kalimat tersebut terdapat penggunaan konjungsi ganda yaitu ataudan bahkan. Sebaiknya dalam sebuah kalimat penulisan konjungsi hanya menggunakan satu konjungsi yang menghubungkan antar klausa.

Perbaikan kalimat tersebut adalah sebagai berikut:

"Jika perpecahan dan rivalitas terus terjadi, maka saya khawatir pijakan bagi stabilitas dan perdamaian yang lestari akan goyah, bahkan akan sirna".

3) Penggunaan Istilah Asing

"Indonesia akan terus memainkan peran sebagai bridge builder".

Pada kalimat di atas terdapat istilah asing yaitu 'bridge builder' yang memiliki makna 'jembatan pembangun perdamaian dunia'.

Perbaikan kalimat tersebut adalah sebagai berikut;

"Indonesia akan terus memainkan peran sebagai jembatan pembangun perdamaian dunia".

Berdasarkan hasil analisis yang telah dilakukan, terdapat kesalahan berbahasa tataran sintaksis. Berikut ini merupakan tabel daftar kesalahan berbahasa tataran sintaksis pada pidato Presiden Jokowi yang diakses pada laman Kompas.com edisi 23 September 2020. 


\begin{tabular}{|c|c|c|c|c|}
\hline No. & Klasifikasi Kesalahan & Jenis Kesalahan & Jumlah Kesalahan & Total \\
\hline \multirow[t]{3}{*}{1.} & \multirow[t]{3}{*}{$\begin{array}{l}\text { Kesalahan } \\
\text { penggunaan struktur } \\
\text { frasa }\end{array}$} & $\begin{array}{l}\text { Penggunaan preposisi } \\
\text { yang tidak tepat }\end{array}$ & 1 & \multirow[t]{3}{*}{4} \\
\hline & & $\begin{array}{l}\text { Penggunaan unsur yang } \\
\text { berlebihan atau } \\
\text { mubazir }\end{array}$ & 2 & \\
\hline & & Penjamakan yang ganda & 1 & \\
\hline \multirow[t]{3}{*}{2.} & \multirow{3}{*}{$\begin{array}{l}\text { Kesalahan } \\
\text { penggunaan struktur } \\
\text { kalimat }\end{array}$} & Penghilangan konjungsi & 1 & \multirow[t]{3}{*}{4} \\
\hline & & $\begin{array}{l}\text { Penggunaan konjungsi } \\
\text { yang berlebihan }\end{array}$ & 2 & \\
\hline & & $\begin{array}{l}\text { Penggunaan istilah } \\
\text { asing }\end{array}$ & 1 & \\
\hline Jumlah & & & & 8 \\
\hline
\end{tabular}

Dari hasil klasifikasi kesalahan berbahasa pada tabel di atas, didapatkan bahwa kesalahan berbahasa terbanyak ditemukan pada kesalahan penggunaan struktur frasa. Terdapat tiga jenis kesalahan dalam penggunaan struktur frasa yaitu penggunaan preposisi yang tidak tepat, penggunaan unsur yang berlebihan atau mubazir, dan penjamakan yang ganda. Kesalahan berbahasa yang selanjutnya yaitu kesalahan penggunaan struktur kalimat. Pada kesalahan ini terdapat tiga jenis yaitu penghilangan konjungsi, penggunaan konjungsi yang berlebihan, dan penggunaan istilah asing.

\section{Simpulan}

Manusia merupakan makhluk sosial. Manusia menggunakan sebuah bahasa untuk berkomunikasi. Bahasa yang baik dan benar harus digunakan agar maksud dapat tersampaikan dengan jelas. Terdapat empat keterampilan berbahasa, yaitu: menyimak, berbicara, membaca, dan menulis. Pidato dapat dikelompokkan ke dalam keterampilan berbicara apabila diucapkan secara lisan dan menulis jika dituangkan ke dalam sebuah tulisan. Sintaksis merupakan salah satu cabang linguistik yang mempelajari tentang frasa, klausa, dan kalimat.

Pada pidato Presiden Joko Widodo dalam Sidang Umum PBB yang dimuat dalam portal Kompas.com edisi 23 September 2020, terdapat 8 kesalahan berbahasa yang termasuk ke dalam tataran sintaksis. Kesalahan tersebut terbagi atas kesalahan penggunaan struktur frasa dan kesalahan penggunaan struktur kalimat. Terdapat 4 kesalahan penggunaan struktur frasa, yaitu: 1 kesalahan penggunaan preposisi yang tidak tepat, 2 kesalahan penggunaan unsur yang berlebih atau mubazir, dan 1 kesalahan penjamakan yang ganda. Kesalahan penggunaan struktur kalimat terbagi atas 1 kesalahan penghilangan konjungsi, 2 kesalahan penggunaan konjungsi yang berlebih, dan 1 kesalahan penggunaan istilah asing. 


\section{DAFTAR PUSTAKA}

Arisanti, T. (2016). Kesalahan Penggunaan Konjungsi pada Karangan Penulisan Bahasa Petunjuk Siswa Kelas VIII SMP N 2 Gatak.

Hasanudin, C. (2018). Kajian Sintaksis pada Novel Sang Pencuri Warna Karya Yersita. Jurnal Pendidikan Edutama, 5(2), 19-30.

Ihsanuddin. (2020, September 23). Lengkap, Isi Pidato Presiden Jokowi saat Sidang Umum PBB. Diakses dari https://amp.kompas.com/nasional/read/2020/09/23/10325641/lengkap-isipidato-presiden-jokowi-saat-sidang-umum-pbb

Johan, G. M., \&Simatupang, Y. J. (2017). Analisis Kesalahan Berbahasa Indonesia secara Sintaksis dalam Proses Diskusi Siswa Kelas IV SDN MIRI. Visipena Journal, 8(2), 241-253.

Lubis, Mina Syanti. (2018). Struktur Penulisan Teks Pidato Mahasiswa Semester III Prodi Pendidikan Bahasa dan Sastra Indonesia Institut Pendidikan Tapanuli Selatan: Kajian Retorika. Jurnal Education and Development Institut Pendidikan Tapanuli Selatan, 4(2), 66-71.

Mubarokah, E., \& Rosita, F. Ya. (2019). Kesalahan Sintaksis pada Esai Siswa (Grammatical Errors ini Student Essay). JALABAHASA, 15(2), 163-172.

Natalia, E. (2017). Analisis Kesalahan Berbahasa Tataran Sintaksis Pada Penulisan Teks Eksposisi Siswa Kelas X SMA Negeri 7 Medan Tahun Pembelajaran 2016/2017(Doctoral dissertation, UNIMED).

Sawalmeh, M. H. M. (2013). Error analysis of written English essays: The case of students of the preparatory year program in Saudi Arabia. English for Specific Purposes World, 14(40), 1-17.

Setyawati, Nanik. (2013). Analisis Kesalahan Berbahasa Indonesia: Teori dan Praktik. Surakarta: Yuma Pustaka.

Somad, Adi Abdul \&Indriani. (2010). Belajar dan Mengenal Teknik Berpidato. Jakarta: Trans Mandiri Abadi.

Uswati, T. S., \& Nuryanto, T. (2018). Kesalahan Sintaksis pada Skripsi Mahasiswa IAIN Syekh Nurjati Cirebon. Indonesian Language Education and Literature, 4(1), 1-10. 